\title{
DIE LONGTOMKANONNE NÁ DIE SLAG VAN DALMANUTHA
}

*Prof B.V. Lombaard

At the beginning of the Anglo Boer War the ZA Republic owned four $155 \mathrm{~mm}$ canon. They are often referred to as Creusot Canon as they were manufactured at Le Creusot in the East of france.

The English preferred to refer to these canon as long Tom, a name by which they also became known among the burghers and civilians. The article below discusses the role and eventual fate of each of these canon after the Battle of Dalmanutha (Bergh- en -dal) which took place during 21-27 August 1900.

\section{Opsomming}

Die datums en plekke waar die vier Long Tom's onderskeidelik vernietig is, word soos volg opgesom:

No. 1 Op naastenby 20 September 1900 op Komatiepoort.

No. 2 Op 18 Oktober 1900 by Letabadrif.

No. 3 Bugenaamd "Die Jood" op ongeveer 16 April 1901, op die plaas Rietfontein 375 KT. sowat $30 \mathrm{~km}$ noordwes van Ludenburg.

No. 4 Op ongeveer 29 April 1901 by Feeskop omtrent agt km noord van Haenertsburg.

Die kanonne het hulle dramatiese bedruwighede dus binne agt maande afgespeel.

\section{Inleiding}

Onder sy grofgeskut het die Z.A. Republiek aan die begin van die Anglo-Boere-oorlog vier $155 \mathrm{~mm}$ kanonne besit. Hulle word dikwels as Creusot-kanonne beskruf omdat hulle te Le Creusot in OosFrankrusk vervaardig is en wel deur die firma Schneider et Cie. Kleiner $75 \mathrm{~mm}$ geskut, wat ook te Le Creusot vervaardig is, word ook soms as Creusotkanonne beskruff.

Die Engelse het die vier grotes Long Tom genoem 'n naam waaronder hulle ook algemeen onder die burgers en siviele inwoners bekend geword het. (Preller (1937) Grobler, p. 186. Steenkamp, p. 83).

Die Long Tom was as ' $n$ vestingskanon ontwerp en die vier forte rondom Pretoria was don ook voor die oorlog elk deur so 'n kanon beman (Ploeger, p. 53).

Die Long Tom se massa tesame met su massiewe sluitstuk was $5700 \mathrm{~kg}$ en sy maksimale trefafstand was ongeveer $9 \mathrm{~km}$. Die projektiele het bestaon vit kartetse en granate met 'n massa van omtrent 40 kg. (Ferreira (red.) p. 228). Wanneer die kanon vervoer word om as veldstuk te dien, word die loo $p$ met ' $n$ katrol gehus en gemonteer o $\rho$ ' $n$ raamwerk

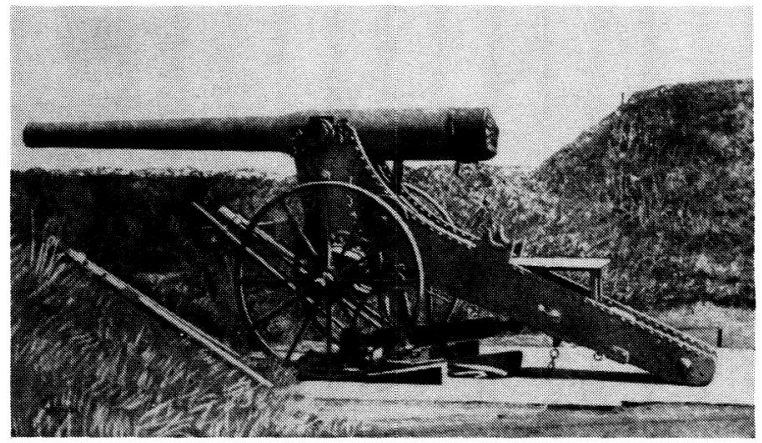

'n long Tom (Creusot) $75 \mathrm{~mm}$ by Skanskop (761004781)

waarop die loop eweredig tussen twee paar wiele kon rus. Die opstel en aftakel van die kanon het dus baie tyd in beslag geneem.

Onder die ander tekortkomings van die Long Tom as veldkanon was die moeilike vervoer van so 'n lomp en swaar toestel oor bergpasse en slegte paaie sowel as die swart kruit waarmee die ammunisie gelaai was en wat met die afvuur daarvan die posisie van die kanon verraai het. (Breuttenbach, J.H. p. 90-91)

\section{Bedrywighede rondom Hectorspruit}

Gedurende die eerste paar weke van September 1900 het Hectorspruit langs die Oosterspoor 'n hoogtepunt van bedruwighede beleef. Op $11 \mathrm{Sep}$ tember het die Z.A. Regering met genl Louis Botha en Schalk Burger as vise-president aan die hoof en waar genl Ben Viljoen ook teenwoordig was, amptelik afkskeid geneem van presidente Kruger en Steun (Ferreira (red.) p. 173. Armery (red.) iv. p. 467).

In plaas van die verdediging van Komatiepoort is besluit dat genl Viljoen en sy kommando op trek sou gaan met waens belaai met soveel bruikbare krugstuig en proviand as wat hulle na Pietersburg kon saamneem. Op 18 September was genl Viljoen reeds op trek maar nie voor alle oortollige voorrade, insluitende sowat 14 kanonne, vernietig en in 
die Krokodilrivier gegooi is nie. (Viljoen, (1903) p 131. Amery (red.) iv, p. 80. Grant (1908) p. 419. Schikkerling, p. 67-68. Penning, p. 1122).

'n Paar ysterwiele wat op land agtergebly het, is in latere vertellings beskruf as behorende aan 'n Long Tom wat op Hectorspruit vernietig is. (Grobler 1965 p. 191). In geen ander bron word daar van 'n sodanige vernietiging melding gemaak nie. Die enigste Long Tom (no. 1) wat 'n ruk in hierdie geweste vertoef het, was steeds op 'n spoorwegwa gelaai op pad na Komatiepoort. Die ander twee Long Toms (no.'s, 2 en 4) was ook nog in diens om genl Buller se ooswacrtse tog te stuit. Toe genl Viljoen Hectorspruit op 17 September verlaat, kon hy dus nie ' $n$ Long Tom by hom gehad het nie en was die een op die spoorwegwa ook nie die enigste een wat nog nie opgeblaas' was nie. (Amery (red.) p. 477). Ewe-eens kan berigte oor die vernietiging van Long Toms op plekke soos Belspruit, Krugersdorp (Krugerspos?) verontagsaam word (Preller, 1937)

\section{Vroeë Veldslae}

Met oorlog teen die twee Republieke klaarblyklik onafwendbaar het mobilisasie van die kommando's op 29 September 1899 begin (Ferreira (red.), voetnoot p. 1 16). Die vier Long Tomkanonne word ook van die forte rondom Pretoria onttrek en val Natal in Oktober 1899 binne. (Ferreira (red.), p. 1 18).

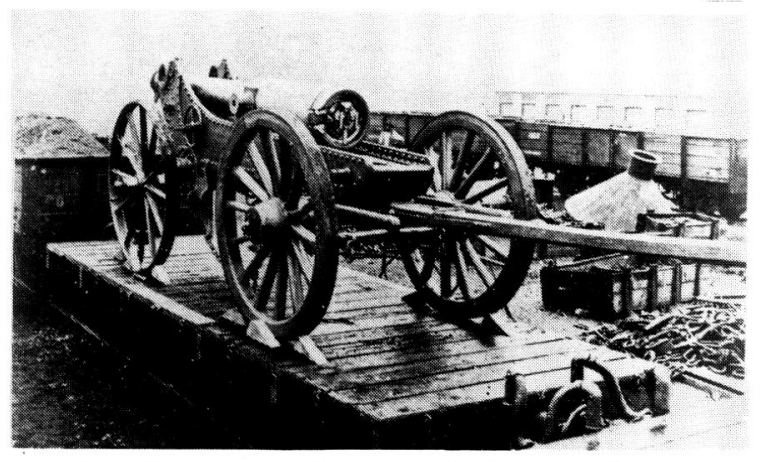

'n long Tom kanon onderweg na die front, word per trein vervoer (771000854)

Dis by Lombardskop, naby Ladusmith, wanr die loop van kanon Nr. 3 op 8 Desember 1899 beskadig is, maar later herstel is en toe die bynaam "Die Jood" gekry het (q.v.)

In Augustus 1900 was die vier Long Toms terug in Transvaal. Drie word strategies opgestel by Dalmanutha, terwyl No. 1 op 'n spoorwa gelaai gestaan het (Amery (red.) iv, p. 441, p. 442; p. 456 met kaart).

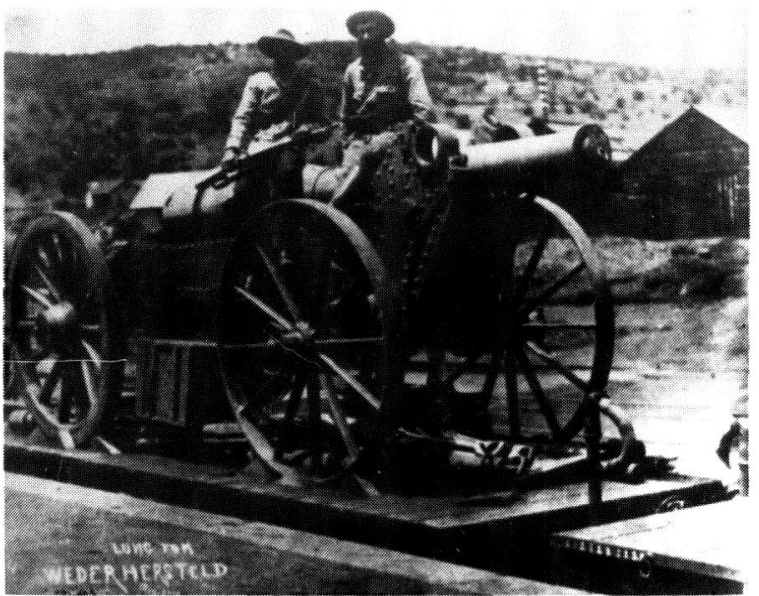

'n Erg beskadigde long Tom kanon is in die werksploas van die Nederlands-Suid-Afrikaanse Spoorwegmaatskappy herstel en is hier onderweg na Kimberley. (771000852)

Na die slag van Dalmanutha (Berg-en-Dal) $21-27$ Augustus 1900, is No's 2, 3 en 4 by "de pannetjes" tussen Belfast en Dullstroom opgestel. (Ferreira (red.) p. 170-172). (Amery (red.) p. 449-453).

Ter herinnering aan hierdie saamtrek is die noam "Long Tom" later aan "n sulun op die spoorweg in die omgewing gegee (Schoeman, (1880-1971) Mondelinge mededeling in 1944). Die nambord is van die huidige teerpad sigbaar.

Kanon No. 3, bygenaamd "Die Jood", is hier aan die Ludenburgse Kommando onder komdt. David J. Schoeman toegewys en het tot aan sy einde in April 1901 nie aktief aan die oorlog deelgeneem nie.

\section{Kanon No. 1}

Hierdie Long Tom is al met die Oosterspoor vervoer en was in die eerste week van September 1900 by genl Viljoen bu Godwanrivier en op Hectorspruit op 17 September. Daarna is hy op Komatiepoort opgeblaas. (Amery (red.) iv. p. 463, p. 477; pp 481 -484. Viljoen (1902) p. 130. Penning p. 1123). Dit is die posisie warin genl Pole-Carew Komatiepoort vind toe hy op 24 September daar acnkom. Hiervan was Lord Roberts reeds bewus want op 20 September kon hy van Nelspruit 'n telegram met sodanige inhoud afstuur (Penning p. 1 125). Alles in aanmerking geneem kan die waarskunlikste datum van die vernietiging op 20 September 1900 gestel word.

\section{Die twee kanonne No.'s 2 en 4}

Toe hierdie twee Long Toms "de pannetjes" verlaat, sou hulle om die beurt met tussenposes aanvallend 
en retirerend in gevegte met die vyand gewikkel wees.

Tussen Spitskop en Witklip, suid van Lydenburg, het die twee kanonne die kamp van genl Buller op Badfontein op 4 September 1900 onder skoot geneem. (Amery (red.) iv, p. 462. Ferreira (red.) p. 172). In die naburige begraafplaas is daar ' $\mathrm{n} v \mathrm{f} F$ tiental grafte van Engelse soldate. Volgens die opskrifte by agt se grafte het hulle in die slag van 4 September gesneuwel. (Die begraafplaas sal mettertud oordek word deur water van die Braam Raubenheimerdam, maar die oorskotte van die gesneuweldes sal deur die S.A. Road vir Oorlogsgrafte herbegrawe word.)

Van Badfontein het genl Buller opgeruk na Lydenburg, warkeen die twee kanonne voorvit beweeg het. Agt km oos van die dorp het die twee Long Toms stelling ingeneem op Paordeplaats vanwaar hulle op 6 September op Buller se kampe rondom die dorp gevuur het. (Amery (red.) iv, p. 465-66, Grobler, 1965 p. 188-89.) Op Buller se besluit om die offensief te neem, moes die kommando met sy twee Long Toms onder genls Botha en Gravett ' verbete agterhoedegeveg ooswaarts langs die Ou Hawepad (Duiwelskneukels) gedurende 8-10 September voer. (Amery (red.) iv, p. 465-67.) Sedert hierdie gedeelte van die pad in Julie 1953 amptelik die Long Tompas genoem is, het die geveg ook onder dieselfde naam bekend geword. Aan Boerekant is kmdt S.B. Buys gewond terwul die Engelse verliese annsienlik moes gewees het, hoewel die getalle van 13 gesneuwel en 25 gewond moontlik die ongevalle van ander gevegsterreine insluit. (Ferreira (red.) voetnoot 267, p. 173. Wilson, I, p. 123).

Tydens die slag van Long Tompas is die bevel oor die Kommando aan genl G. Gravett oorhandig, want genl Botho is, sy ongesteldheid ten sput, no Hectorspruit ontbied om daar op 11 September van die presidente Kruger en Steyn afskeid te neem. Genl Gravett se opdrag was om die pad oor Pilgrim's Rest veilig te hou vir pres M.T. Steun se deurtog na die weste en ook later vir genl Lovis Botho met die staatskis. Dit het Grovett reggekry en kon pres Steun en sy staf op Pilgrim's Rest gefotografeer word. (Marshall, Plaat NO. 10). Genl Botha is later ook veilig langs dieselfde pad deur.

Intussen is die twee long Toms (No's 2 en 4) in die donker of na Sabie met Buller kort op hulle hakke. Toe Buller op 21 September op Sabie aankom was die twee Long Toms reeds voorvit en hier iewers het die twee van mekaor geskei.

\section{Kanon No. 2}

Die pad wat Long Tom No. 2 van Sabie gevolg het, kon nie presies vit die geskiedskruwing vasgestel word nie. Die warskunlikste roete is oor Kowunspas of Abel Erasmuspas na die Laeveld. Hierlangs het dit die spoor van gen/ Viljoen se trek gevolg om op 18 Oktober 1900 op Letabadrif opgeblaas te word. (M.E.R. p. 88). Uit oorkondes kon twee getuies die juiste plek in die Letabarivier aandui. (Grobler, 1982 p. 11 ).

\section{Kanon No. 3 (Die Jood)}

Gedurende die beleg van Ladusmith was 'n Long Tom op die naburige Lombardskop opgestel. In die nag van 8 Desember 1899 het ' $n$ Engelse patrollie die bek van die kanon met plofstof beskadig. Nadat die skade in die werkplaas van die Z.A. Spoorwegmaatschappy in Pretoria herstel is, was die loop korter en het die kanon die bynaam "Die Jood" gekry. (Anon. Militaria. p. 40 Viljoen (1973) p. 68. De Souza, p. 140. Ferreira (red.) Voetnoot, p. 128).

Na die slag van Dalmanutha trek Die Jood saam met die Ludenburgse kommando onder kmdt David J. Schoeman noordwarts langs Steenkampsberg en kampeer wes van Lydenburg. Hier word sy verlate kamp in 'n knyptangbeweging onder aanvoering van genl Walter Kitchener op 31 Oktober 1900 ingeneem (Grant (1908), p. 437). Komdt Schoeman word egter nie agtervolg nie en kon hy weer laertrek op 'n plek vanwaar hy op die Engelse in Lydenburg kon spioeneer. Op 2 Februarie 1901 was No. 3, Die Jood, nog by sy kommando (M.E.R. ค. 132).

Toe die vyand sy aanvalle in April herhaal was daar van komdt Schoeman se kommando, verswak deur wekelange ledigheid, geen sprake van teenstand nie, veral omdat die Long Tom reeds voorvit was in die rigting van Rietfontein $375 \mathrm{KT}$, die plaos van Klaas Prinsloo (1844-1902) aon Watervalsrivier sowat $30 \mathrm{~km}$ noordwes van Lydenburg ( $M \in$. R. p. 160-170.) (Die naburige plaas Bergfontein, wat su noem, moet as 'n vergissing vir Rietfontein beskou word).

Die veertienjarige Elsje Magdalena Prinsloo (geb. 11.6.1887), later mev Swart, kon op 12 Julie 1979 en ook 14 jaar tevore, presies vertel hoe haor vader se osse die Long Tom getrek het tot op die koppie, vanwaar dit die canrukkende Engelse op Naaumpoort onder skoot kon kry. (Grobler, (1965) p. 187-188. Mondelinge verklaring deur mev Swart op 12 Julie 1979). Die Jood is op die koppie opgeblaas nadat die laaste paar projektiele op 
ongeveer 15 of 16 April 1901 afgevuur is (Grant (1910) IV. p. 141).

J. Niewenhuize, eertudse L.V. vir Ludenburg, het ook op 'n gedeelte van Rietfontein gewoon. Hy het vooraf die visier van die Long Tom verwuder en su dogter, mev. Piet Joubert en hulle seuns het die visier bewaar en dit in bruikleen aan die Lydenburgse Museum geskenk. Stukke van die loop afkomstig van die koppie word ook in die lydenburg-Museum bewaar. (Grobler (1965) p. 187-188). Gedurende 1982 kon die LydenburgMuseum met behulp van 'n metaalverklikker ' $n$ verdere stuk van die loop opgrawe. Die juiste koppie is gemerk met die hoogte 4808 voet op Blad 2430 cc op die skaal 1:50000.

\section{Kanon No. 4}

Na beveiliging van die bergpasse het genl Gravett met Long Tom No. 4 na Pilgrim's Rest getrek waor dit gehaal is deur ' $n$ boer se osse no Ohrigstad (Amery (red.) iv p. 479, Ferreira p. 174, Breitenbach: Herinneringe) Intussen het genl Buller op 1 Oktober op Krugerspos laergetrek en hier het genl Gravett hom aangeval, met No. 4 en twee ander kanonne wat tien ongevalle, een gesneuwel en die res gewond, veroorsaak het. (Amery (red.) iv. p. 480).

Hierna is genl Gravett oor die buna onbegaonbore Klipkloof na Bothasberg (omgewing van Stoffberg) om daar by genl Botha aan te sluit. Op hierdie reis is genl Gravett in 'n skermutseling gewond en is hy sowat twee weke later op 26 Oktober 1900 oorlede (Preller (1916) p. 161). In daardie dae is daar blukbaar besluit om die weerstand teen die naderende vuand in Noord-Transvaal te versterk met Pietersburg as hoofkwartier. Eerstens word dit gedoen deur genl Beyers, wat toe op Lydenburg tot asst komdt genl oor die noordelike kommandement bevorder is, na Pietersburg te beveel. Hy verlaat Ludenburg op 5 September, trek oor die ou bergpas wes van die hedendaagse Strudomtonnel en laat sy "spreuk" "God is met ons" op 'n kremetartboom aan Olifantsrivier vitkerf en kom twee weke later op Pietersburg aan. (Naude p. 161) ${ }^{2}$

Tweedens word Long Tom No. 4 van Bothasberg na Pietersburg gestuur om daar by genl Beyers aan te sluit. Die pad waarlangs die kanon getrek het, is nie gedokumenteer nie maar dit kan dieselfde wees wat genl Viljoen en S.P.E. Trichard die vorige November van Pietersburg na Bothasberg gevolg het (M.E.R. p. 89-91). Dit sou dan lui: Bothasberg, Mosepsdrif (omgewing Groblersdal) en verder langs Olifantsrivier oor Smitsdorp tot op Pietersburg.

Toe genl Plumer Pietersburg op 8 februarie 1901 binneval, het genl Beyers die dorp die vorige dag met Kanon No. 4 verlaat. (Amery (red.) v. p. 203). Die enigste voorval waarin No. 4 in hierdie gebied gebruik is, het plaasgevind onmiddellik voor su vernietiging op feeskop, so genoem ondat geloftefees (Dingaansfees) in die verlede daar gehou is. (Grobler (1965) p. 189). Die kop is geleë langs Driehoeksbaken No. 85, sowat $8 \mathrm{~km}$ noord van Haenertsburg. Terwul genl Beyers betrokke was in 'n geveg by fort Kliipdam, $27 \mathrm{~km}$ noord van Pietersburg, verlact kol Grenfell Pietersburg op 26 April op soek na die Long Tom wat volgens inligting hom iewers oos van Pietersburg bevind. Toe hy op 29 April deur Houtbosberg trek, word hy deur projektiele van die Long Tom begroet tot op 'n afstand van 3000 tree, net om die kanon aan stukke te vind. Die waarskunlikste datum van die vernietiging van Long Tom No. 4 is dus 29 April 1901. (Grant (1910) iv p. 438).

Terselfdertud sit ofdelings van genl Plumer hulle . soektog voort en toe hulle $23 \mathrm{~m}$ l (37 km) verder oos op die plaas Bergplaats op 30 April aankom vind hulle die kanon aan stukke (Amery (red.) iv. p. 438). Die plaas Bergplaats (wat later in drie plase verdeel is) verskun nog op Blad 11 (Leudsdorp) van Major Jackson Series en is $11 \mathrm{~km}$ wes van feeskop geleë, wat glad nie ooreenstem met die posisie van Feeskop nie.

Ter opheldering van die teenstrudigheid is ondersoeke voortgesit. Uit oorlewering het prof Lovis Changuion van Haenertsburg veelseggende getuienis opgespoor ten gunste van feeskop. Op versoek het die Weermag vit Pretoria goedgunstig hulp verleen deur kol Malan en $\mathrm{kpl}$ du Toit of te staan om met 'n metaalverklikker na oorblufsels te soek. Die ondersoek is op Feeskop langs Driehoeksbaken No. 85 op 31 Augustus 1982 onderneem. Oor in gebied van 'n paar vierkante meters en op ' $n$ diepte van minder as $20 \mathrm{~cm}$ is op aanuysing van die verklikker, spoedig etlike stukke metaal opgegrawe, insluitende drie brokstukke klinknaels met aangehegte koppe en 'n stuk $10 \times 10 \mathrm{~cm}$ van 'n kanonloop met tipiese riffels (groewe) van 'n long Tom se kanonloop.

Uit hierdie vondse en stawende getuienis kan daar nou oortuigend aangeneem word dat die laoste van die vier long Toms op Feeskop opgeblaas is, waarskụnlik op 29 April 1901. 


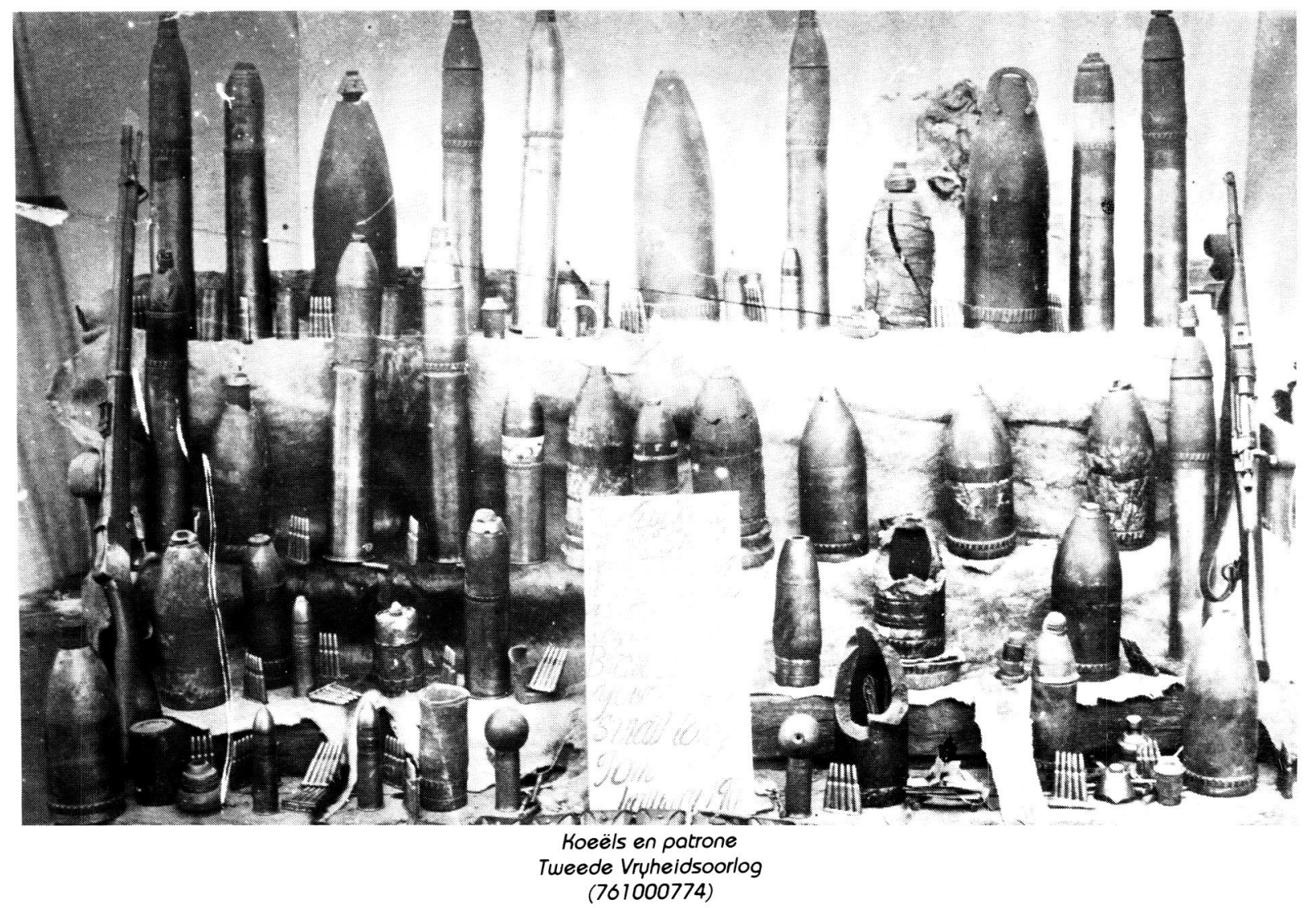

SERVICES DE LARTILLERIE \& DES FORTIFICATIONS

MATERIEL DE CAYPAGNE A TIK RAPII)E SYSTEME SCHNEIIDER-CANFI

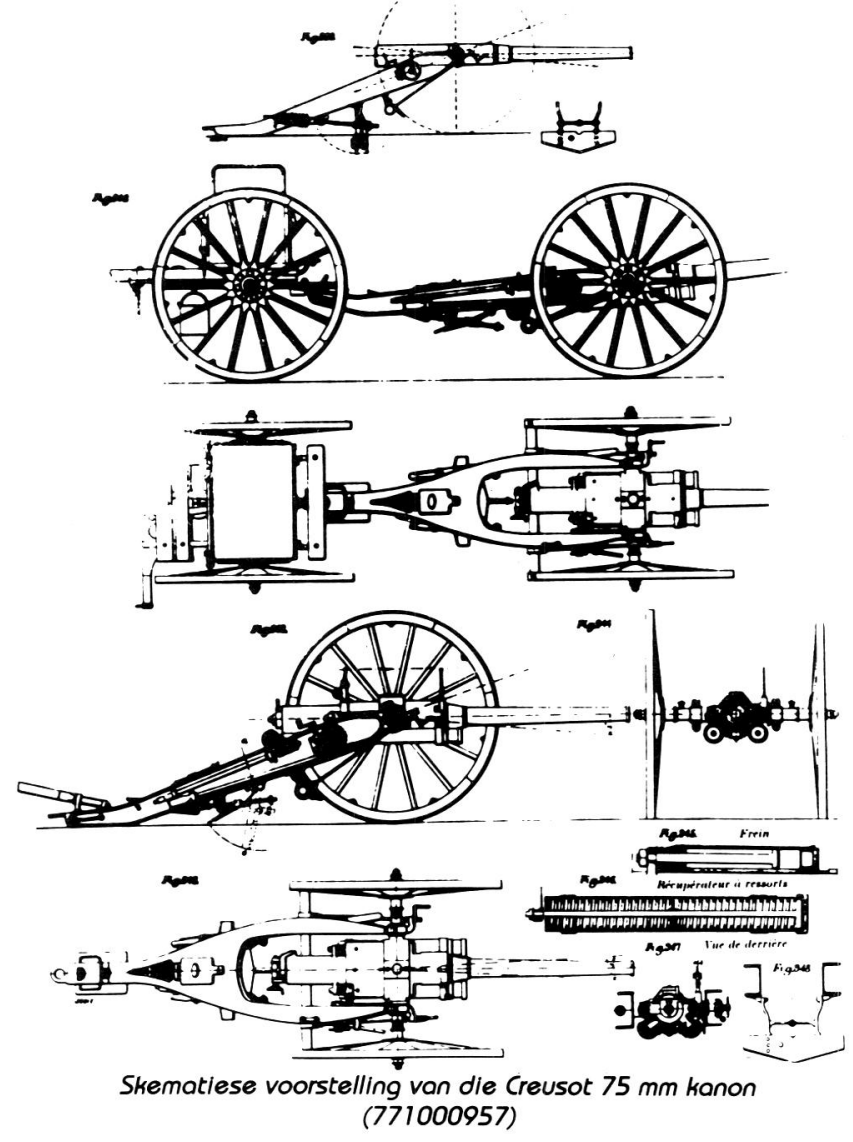




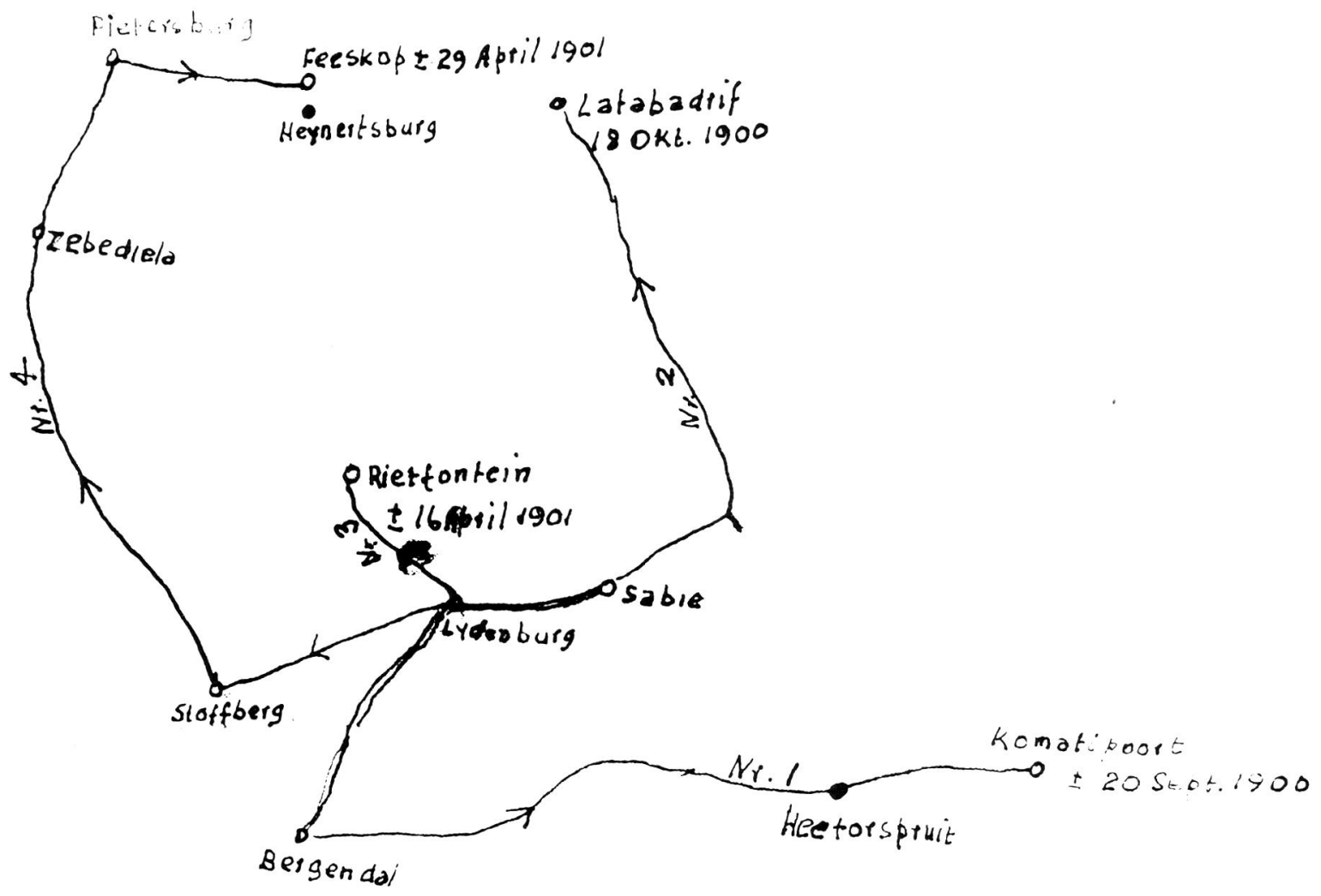

SKETS VAN DIE TREKROETES VAN DIE LONGTOMKANONNE NÁ DIE SLAG VAN DALMANUTHA Vitleg gegrond op amptelike kaorte (Staatsdrukker)

(84 1002506)

*Prof B.V. Lombaard Ph.D., D.Sc

\section{Geraadpleegde Bronne}

AMERY, L.S. (red.) The times history of the war in South Africa 1899-1902. iv-v, London, 1906

(ANONIEM) Militaria 4/4 1974

BREYTENBACH. J.H. Die geskiedenis van die Tweede Vruherdsoorlog in Suid-Afriko 1899-1902. II Pretoria; 1971.

BREITENBACH, J.J. (Sr.) Herinneringe van 'n baanbreker. Ongepubliseerde herinneringe. Boek I. J.5. Martiz, pp. 48-157. Eksemplaar ook in Ludenburgse Museum.

DE SOUZA, C.W.L. No charge for delivery. Books of Africa 1969

FERREIRA, O.J. O. (red.) Geschiedenis werken en streven van S.P.E. Tri. chard R.G.N. Pretoria, 1975.

GRANT. M.H. History of the war in South Africo 1899- 1902. Vol. III Hurst $\&$ Blackett, London, 1908.

GRANT. M.H. History of the war in South Africa 1899-1902. IV Hurst $\&$ Blackett, London, 1910

GROBLER, D.C. Die Long Toms: wat het van hulle geword. Hostorio $\times 3$ 1965.

GROBLER, D.C. Geskiedenis van die Long Tom-pas. Ludenburg Nuus 3/2/1982

MARSHALL, Alex, Photos of Boer Commandos.

M.E.R. Oorlogsdagboek van 'n Transvaalse burger te velde 1900-1901. Tafelberg, Kaapstad, 1976
NAUDE, J.F. Vechten en viuchten van Beyers en Kemo. Rotterdam. 1903. PRELLER. G.S. Die vier Long Toms. Die Huisgenoot 28/5/1 937

PLOEGER, J. The fortification of Pretoria- Pub. I. Govt. Printer, 1908.

PENNING, L. De oorlog in Zuid-Afrika- Rotterdam, 1904.

PRELLER, G.S. Koptein Hindon. Pretoria. 1916.

ROTHMAN, F.L. Oorlogsdagboek. Kuk M.E.R.

SCHIKKERLING, R.W. Commondo Courageous. Hugh Keartland, Johannesburg, 1964

SCHOEMPN. S.J. (1880-1971) Mondelinge mededeling, Rusploas. 1944. STEENKAMP, W. Die laaste Long Tom. Ster 1 1/8/1972.

SWART. E.M. (oeb. Prinsloo 11/6/1887) Verklaring Doornhoek 1/27/1970.

VIUOEN, B.J. Mune herinneringen vit den Anglo-Boeren-oorlog. Amsterdam, 1902.

VIUOEN, Ben. MU reminiscences of the Anglo-Boer Wor. Struik, Cape Town. 1973.

WILSON. H.W. After Pretorio. London, 1902.

\section{Voetnotas}

1. Die woord "opblaos" met die betekenis van "in die lug spring" het hom sodanig ingeburger dat dit nie meer gekeer kon word nie. Kuk prof. Piet Cillië in "Joernalistiek vandag en Beeld 25.5. 1982

2. Die spreuk is vermoedelik na acnleiding van Matteus 1:23 en ook Jesoja 8:10. 